\title{
JURISPRUDENCIA NACIONAL, NUEVOS Tribunales Ambientales y DeRecho INTERNACIONAL DEL MEDIO AMBIENTE
}

[Chilean Jurisprudence, New Environmental Courts and International Environmental Law]

\author{
Osvaldo Urrutia Silva* \\ Pontificia Universidad Católica de Valparaíso
}

\begin{abstract}
RESUMEN
El artículo se refiere a la jurisprudencia de los tribunales superiores de justicia en materias ambiental y al rol que pueden desempeñar los Tribunales Ambientales creados por la Ley $\mathrm{N}^{\circ} 20.600$ en materia de implementación, interpretación y cumplimiento del Derecho internacional del medio ambiente.
\end{abstract}

\section{Palabras clave}

Derecho internacional del medio ambiente - Jurisprudencia ambiental Tribunales ambientales.

\section{Abstract}

This article refers to jurisprudence of the Supreme Court on environmental matters and to the role the Environmental Courts created by Act No. 20,600 may perform regarding the implementation, interpretation and enforcement of the International environmental law.

\section{KEYWORDS}

International environmental law - Environmental jurisprudence - Environmental courts.

RECIBIDo el 30 de marzo y ACEPTADo el 22 de mayo de 2013

* Magíster en Derecho por la Universidad de Londres. Profesor en la Facultad de Derecho de la Pontificia Universidad Católica de Valparaíso. Dirección postal: Avenida Brasil 2950, Valparaíso, Chile. Correo electrónico: osvaldo.urrutia@ucv.cl Mis sinceros agradecimientos al profesor Dr. Manuel Núñez Poblete (PUCV) por sus valiosos comentarios. Por supuesto, todos los errores e imprecisiones son de mi exclusiva responsabilidad. 


\section{INTRODUCCIÓN}

Es innegable que una de las áreas del derecho internacional que ha evolucionado más intensamente en las últimas décadas es la protección del medio ambiente. Chile no es ajeno a este desarrollo y ha sido parte activa en los procesos de negociación para alcanzar acuerdos en materia ambiental, y también lo es en la mayoría de los regímenes multilaterales relevantes sobre la materia.

Las obligaciones que se acuerdan en el plano internacional necesitan por regla general de actos posteriores de implementación en el ámbito nacional. Ellas pueden provenir del poder legislativo, de la administración o del juez. Precisamente, el rol que le cabe a los tribunales nacionales en la implementación y cumplimiento del derecho internacional del medio ambiente no ha recibido especial atención por parte de nuestra doctrina y jurisprudencia. Ello obedece a múltiples razones que van desde la falta de especialización en la materia hasta cierta reticencia por parte de los tribunales cuando se trata de aplicar directamente el derecho internacional para resolver un caso específico de contenido ambiental.

En el contexto y frente a las intensas modificaciones a la legislación ambiental introducidas por las Leyes $\mathrm{N}^{\text {os }} 20.417$ y 20.600 , surgen diversas interrogantes que resulta pertinente analizar. Una de ellas consiste en analizar el rol de los nuevos tribunales ambientales en la implementación y cumplimiento de obligaciones internacionales en materia de protección del medio ambiente. Esto resulta interesante de abordar no solo frente a la importancia creciente que adquiere este derecho, sino también en atención a dos factores de actualidad. El primero de ellos es la tendencia jurisprudencial reciente de la Corte Suprema en virtud de la cual comienzan a abandonarse consideraciones de excesiva deferencia hacia la administración cuando se trata de controlar actos administrativos de contenido ambiental en el marco del Sistema de Evaluación de Impacto Ambiental (en adelante: SEIA). El segundo se debe a que, en virtud de la Ley $\mathrm{N}^{\circ} 20.600$, a contar del 12 de junio de 2013 estaremos frente una judicatura ambiental especializada plenamente operativa.

Este artículo argumenta que el rol de los tribunales chilenos en la implementación del derecho internacional del medio ambiente ha sido hasta ahora limitado, poco relevante y no exento de contradicciones. Sin embargo, aceptando el actual escenario judicial respecto de la aplicación del derecho internacional en Chile -donde parece medianamente claro que los tribunales nacionales han aplicado derecho internacional convencional reconociendo la noción de cláusulas o normas au toejecutables-, los nuevos tribunales ambientales pueden convertirse en una oportunidad para que el derecho in- 
ternacional del medio ambiente reciba un análisis más profundo, en especial, respecto de obligaciones internacionales asumidas por Chile y que dicen relación con acciones que deben adoptarse o evitarse dentro de los espacios sujetos a la soberanía nacional. Al mismo tiempo, se sostiene que hay lugar para que ciertos aspectos del desarrollo doctrinario internacional de este derecho puedan ser analizados con mayor detención por nuestros tribunales y estén disponibles para ser utilizados como una herramienta de interpretación. Se reconocen, con todo, las dificultades que subyacen en la aplicación directa del derecho internacional a todo evento, sin una reflexión acabada sobre las consecuencias que podrían acarrear los eventuales excesos del juez nacional actuando como juez de derecho internacional en la consistencia de nuestro ordenamiento jurídico interno y en las relaciones constitucionales adecuadas entre los poderes del Estado.

El trabajo se divide en dos partes. La primera expondrá la escasa jurisprudencia relevante de nuestros tribunales superiores de justicia relativa a la implementación o aplicación del derecho internacional ambiental. La segunda parte analizará si frente a la reforma introducida por la Ley $\mathrm{N}^{\circ} 20.600$, es posible esperar de nuestra nueva judicatura especializada una nueva mirada y cuáles podrían ser algunas de las áreas donde existe tal espacio. Se finaliza con las conclusiones y postulados pertinentes.

Conviene aclarar que si bien numerosos fallos citados dicen relación con áreas silvestres protegidas, este artículo no tiene por objeto exponer el estado de la cuestión ni proponer un marco regulatorio sustantivo que supere el actual caos normativo existente en la materia. También es necesario advertir que una discusión acabada acerca de las relaciones entre el derecho internacional y el derecho interno, en donde falta todavía mucho por reflexionar y construir -lo cual es extensivo especialmente a materias ambientales-, escapa a las pretensiones de este trabajo.

\section{IMPLEMENTACIÓN Y APLICACIÓN \\ Del Derecho internacional del medio ambiente POR LOS TRIBUNALES SUPERIORES DE JUSTICIA EN CHILE}

Los tribunales ordinarios han conocido profusamente materias ambientales desde mediados de los años ochenta, principalmente a través del recurso de protección, y partir de la Ley $\mathrm{N}^{\circ} 19.300$ por la acción por daño ambiental e impugnaciones o sanciones en el marco de la evaluación ambiental. Sin embargo, los casos relacionados con el cumplimiento o incumplimiento del derecho internacional ambiental no son abundantes, por no decir que derechamente escasos; nuestra jurisprudencia ha conocido de ellos mayorita- 
riamente a través del recurso de protección. Entre las razones de lo anterior es posible señalar:

i) Aunque nuestro ordenamiento jurídico admite en principio la aplicación directa del derecho internacional -la práctica lo demuestra respecto de las llamadas disposiciones autoejecutables, especialmente en casos relacionados con derechos humanos-, los tribunales han evitado aplicar directamente normas de tratados ambientales sin normativa de implementación.

ii) La mayoría de los tratados ambientales contienen obligaciones de carácter horizontal, es decir, aquellas que regulan relaciones estrictamente entre Estados y que como consecuencia no otorgan derechos directamente a los particulares para ser invocados ante el juez (por oposición a las que se podría calificar de verticales, en que los Estados acuerdan regular directamente vínculos entre el Estado y privados) ${ }^{1}$. De esta forma, el ámbito de acción de los tribunales queda considerablemente reducido.

iii) La estructura del recurso de protección - principal contencioso administrativo- no facilita, desde luego, el análisis e implementación del derecho internacional. Además hasta hace muy poco nuestra jurisprudencia aplicó criterios de excesiva deferencia con la calificación administrativa de los proyectos ambientales, sin entrar al análisis de fondo de la evaluación realizada. Esto hizo que los argumentos estrictamente ambientales no siempre se analizaran en su debida profundidad.

iv) Los jueces nacionales no están todavía familiarizados con la evolución del derecho internacional del medio ambiente. Por ejemplo, en los pocos fallos en que se invocan principios de carácter ambiental no aparecen claras las diferencias entre prevención y precaución, confundiendo ambos conceptos. De la misma forma, en algunos fallos se deja entrever fundamentos que se originan o son propios del derecho internacional ambiental, pero que no se invocan como tales.

${ }^{1}$ SLoss, David, The Role of Domestic Courts in Treaty Enforcement (New York, Cambridge University Press, 2009), p. 1. La importancia de esta clasificación es que tratándose de obligaciones de carácter horizontal, características de tratados ambientales multilaterales, el rol de la implementación judicial, si bien no está y no debería estar excluido, es bastante menor. A diferencia de obligaciones típicamente de carácter vertical -por ejemplo, tratados de derechos humanos en los cuales los Estados parte se obligan a reconocer, respetar y dar protección a ciertos derechos reconocidos a los ciudadanos o personas que se encuentran en el territorio de un Estado que es parte de dicho acuerdo, o tratados de inversiones en que se permite a una persona jurídica recurrir directamente contra el Estado-, en la implementación de las obligaciones que emanan de los tratados ambientales -en los cuales comúnmente no se otorgan derechos de aplicación directa a favor de personas naturales o jurídicas- es cierto que por lo general el rol preponderante corresponderá al poder legislativo y a la administración. 
v) A lo anterior se agrega, hasta la Ley $\mathrm{N}^{\circ} 20.600$, la falta de algún grado de especialización en la judicatura.

La lectura de los casos relevantes en Chile ${ }^{2}$ no permite extraer criterios generales o tendencias jurisprudenciales de forma clara, o sostener que existe un tratamiento sistemático de los conceptos y criterios propios del derecho internacional ambiental aplicables internamente. Con todo, el análisis de la jurisprudencia nacional permite comprobar que los tribunales sí han implementado y aplicado derecho internacional del medio ambiente tanto de forma directa como indirecta. La mayoría de estos casos ocurre con ocasión de la impugnación judicial de la evaluación ambiental de proyectos o en relación con actuaciones específicas de la autoridad administrativa. No hay, por el contrario, casos recurrentes en materia de reparación de daño ambiental o respecto de la aplicación de sanciones administrativas. La gran mayoría de los casos se refieren a la aplicación de tratados internacionales y no a otras fuentes del derecho, aunque hay algunas pocas situaciones relacionadas con la aplicación de principios propios del derecho ambiental general.

A continuación se presentan resumidamente los aspectos que se han considerado relevantes para efectos de esta trabajo, respecto de los fallos analizados, proponiendo cuatro categorías que obedecen a un intento forzado por agrupar la escasa jurisprudencia de nuestros tribunales superiores de justicia en la materia (Cortes de Apelaciones y Corte Suprema) bajo criterios medianamente coherentes. Esta presentación no es exhaustiva y no significa que estén todos los casos que representan la jurisprudencia potencialmente relevante.

\section{Aplicación Directa o indirecta Del Derecho} INTERNACIONAL DEL MEDIO AMBIENTE

1. Caso "Proyecto Cascada Chile" y reconocimiento tácito de tratados con disposiciones horizontales.

Algunos fallos reconocen implícitamente la diferencia entre la aplicación de tratados que contienen normas de tipo horizontal o vertical, y las consecuencias que derivan de ello. En el caso "Proyecto Cascada Chile", referido a la aprobación ambiental de un proyecto de explotación de bosque nativo en la $\mathrm{X}$ región, se aprecia esta distinción. La sentencia de la Corte de Apelaciones de Puerto Montt de fecha 16 de agosto de 1999, confirmada por la Corte Suprema, analiza el argumento de los recurrentes en el sentido de si las disposiciones del Convenio sobre diversidad biológica de 1992 son

${ }^{2}$ En especial, gracias al trabajo recopilatorio del profesor Cordero VeGA, Luis, Jurisprudencia ambiental. Casos Destacados, (Santiago, LegalPublishing Chile, 2012). 
aplicables al caso en cuestión, en particular los artículos 14 numeral 1, letra a) y Anexo I de dicho tratado ${ }^{3}$. La Corte resolvió en el considerando $19^{\circ}$ que: "el Convenio sobre Diversidad Biológica solo establece obligaciones para los Estados suscriptores, entre los que se incluye Chile, materia ajena a la aprobación o rechazo de un EIA" (estudio de impacto ambiental). De esta forma, se reconoce que existen algunos tratados que contienen obligaciones que imponen deberes a los Estados partes que a su vez deberán ser implementadas por actos legislativos o administrativos posteriores, y en donde el rol del juez no puede, en principio - por aplicación de las normas del ordenamiento constitucional chileno-, suplirla.

2. Aplicación directa de normas del Convenio $N^{\circ} 169$ de la Organización Internacional del Trabajo en el contexto del SEIA: caso "Parque Eólico Chiloe".

Existen casos en que las cortes nacionales han implementado derecho internacional en el sentido de aplicarlo para un caso concreto como fundamento de la decisión o resolviendo el contenido y extensión de la aplicación de nomas internacionales. Los ejemplos recientes más conocidos son aquellos relacionados con la implementación del Convenio 169 de la Organización Internacional del Trabajo (Convenio 169 OIT), en particular, con la obligación de consulta y el derecho de participación ciudadana en los procedimientos de evaluación de impacto ambiental. Si bien se trata de un tratado que impone obligaciones a los Estados parte y que en tal sentido podríamos llamar horizontal, nuestra jurisprudencia ha implementado algunas de sus normas de manera directa, reconociéndolas como un derecho de participación y deber específico de consulta en favor de los pueblos indígenas. Uno de estos casos se dio a propósito de la evaluación ambiental del proyecto "Parque Eólico Chiloé" , en donde la Comunidad Indígena Antu Lafquén de Huentetique interpuso recurso de protección contra la entonces Comisión Regional del Medio Ambiente (en adelante COREMA) de la Región de Los Lagos, por cuanto en el procedimiento que llevó a dictar la Resolución $\mathrm{N}^{\circ} 373$ de 2011, que calificó favorablemente el mencionado proyecto de parque eólico, no se respetó el deber que tienen los gobiernos, en virtud del artículo $6^{\circ}$ numeral 1 del Convención 169 OIT, de "consultar a los pueblos

${ }^{3}$ Artículo 14, numeral 1, letra a): cada Parte Contratante "Establecerá procedimientos apropiados por los que se exija la evaluación del impacto ambiental de sus proyectos propuestos que puedan tener efectos adversos importantes para la diversidad biológica con miras a evitar o reducir al mínimo esos efectos y, cuando proceda, permitirá la participación del público en esos procedimientos".

${ }^{4}$ Recurso de protección "Comunidad Indígena Antu Lafquén de Huentetique con COREMA de la Región de Los Lagos”, Corte Suprema, rol N 10090-2011. 
interesados, mediante procedimientos apropiados y en particular a través de sus instituciones representativas, cada vez que se prevean medidas legislativas o administrativas susceptibles de afectarles directamente".

La Corte de Apelaciones rechazó el recurso, pero la Corte Suprema revocó el fallo, otorgando la protección pedida y ordenando un nuevo estudio de impacto ambiental. El reproche de ilegalidad del acto impugnado fue precisamente el haber faltado al deber de consulta a los pueblos indígenas según lo dispone el Convenio 169 de la OIT. La Corte señaló que dicho tratado "establece para aquellos grupos con especificidad cultural propia, un mecanismo de participación que les asegura el ejercicio del derecho esencial que la Constitución Politica consagra en su articulo primero a todos los integrantes de la comunidad nacional, cual es el de intervenir con igualdad de condiciones en su mayor realización espiritual y material posible. De ello se sigue que cualquier proceso que pueda afectar alguna realidad de los pueblos originarios, supone que sea llevado a cabo desde esa particularidad y en dirección a ella" $\left(\right.$ considerando $5^{\circ}$ ). En consecuencia, la resolución aprobatoria es ilegal al no realizar este proceso de consulta.

Existen otros fallos posteriores que confirman esta aplicación directa del Convenio 169, en virtud de lo cual se revocan actos administrativos ordenando nuevos estudios de impacto ambiental que se deberán sujetar "a los términos del Convenio 169", y se asegura el derecho a la participación ciudadana de las comunidades indígenas ${ }^{5}$. Este criterio es particularmente relevante porque confirma que aun sin existir legislación o regulación administrativa de implementación (que establezca por ejemplo los términos mínimos de consulta, plazos y formalidades, entre otros), los tribunales han aplicado esta disposición internacional de manera directa para la solución de un conflicto con características ambientales. Se trata, indudablemente, de una norma que nuestra jurisprudencia ha considerado a u to ejecu table, lo cual es consistente con la decisión que el Tribunal Constitucional pronunció en el caso Rol 309, del 4 de agosto de $2000^{6}$. Los artículos 6 y 15 numeral 2 del Convenio 169 fueron declarados autoejecutables por el Tribunal Constitucional, y la Corte Suprema los ha aplicado de dicha forma.

${ }^{5}$ Por ejemplo, el fallo de la Corte Suprema en recurso de protección "Marcelo Condore Vilca con Comisión de Evaluación de la I Región de Tarapacá, 'Sondajes de Paguanta", de fecha de 30 de marzo de 2012, rol N 11040-2011.

${ }^{6}$ Sentencia del Tribunal Constitucional de Chile, rol No 309 , del 4 de agosto de 2000, que rechazó recurso de inconstitucionalidad en requerimiento formulado por diversos diputados de la República para que el tribunal resuelva sobre la constitucionalidad del Convenio $\mathrm{N}^{\circ} 169$, sobre Pueblos indigenas y tribales en paises independientes, adoptado por la Organización Internacional del Trabajo el 27 de junio de 1989. 


\section{Medio ambiente acuático.}

No existe jurisprudencia de nuestros tribunales superiores de justicia particularmente destacada en relación con la implementación de tratados internacionales que regulan regímenes de contaminación. Uno de los pocos fallos que existen se dictó hace más de dos décadas en el caso "Contaminación en el Valle del Huasco", en donde el Protocolo para la protección del pacifico sudeste contra la contaminación proveniente de fuentes terrestres fue uno de los fundamentos para decidir en favor de los recurrentes.

La Corte de Apelaciones de Copiapó, en fallo de fecha 22 de junio de $1992^{7}$, confirmado por Corte Suprema, se refirió a la aplicación directa de obligaciones internacionales en contra de un particular. La Corte de Copiapó acogió el recurso de protección presentado por agricultores y sindicatos de pescadores artesanales del Valle del Huasco en contra de la Compañía Minera del Pacífico, por contaminación atmosférica y de relaves depositados en el mar en una zona aledaña a Bahía Chapaco, cerca del valle del Huasco y Freirina, proveniente de la fábrica de "pellets" de dicha empresa. El fallo ordena medidas de protección por vulneración al artículo $19 \mathrm{~N}^{\circ} 8 \mathrm{CPol}$., entre las cuales se encuentran acciones para mejorar la calidad del aire y otras para neutralizar las consecuencias negativas de las descargas de contaminantes en el medio marino. Precisamente, al abordar la contaminación del entorno marino la Corte resolvió que la actividad de la empresa es ilegal por atentar contra diversos cuerpos legales, y señaló en su considerando 43 letra d) que: "se infringe también por la acción contaminante que provoca la recurrida el Protocolo para la Protección del Pacifico Sudeste contra la Contaminación proveniente de Fuentes Terrestres y sus Anexos, promulgado por Decreto Supremo $N^{\circ} 295$ del año 1986, en donde en su artículo III se establece bajo el epigrafe de 'Obligaciones Generales', que laspartes contratantes se esforzarán por prevenir, reducir o controlar la contaminación del medio marino proveniente de fuentes terrestres, cuando produzcan o puedan producir efectos nocivos tales como daños a los recursos vivos y la vida marina, peligros para la salud humana, obstaculización de la actividades marinas, incluso pesca y otros usos legitimos del mar, deterioro de la calidad del agua del mar para su utilización y menoscabo de los lugares de esparcimiento".

Hay dos elementos que llaman la atención. El primero es que -al igual que en los casos citados en el numeral anterior- en este considerando la Corte hace una aplicación directa de una norma internacional: los actos de vertimiento al mar que realiza la empresa en cuestión son ilegales porque atentan contra una norma de derecho internacional que es parte del ordenamiento

7 “Homero Callejas Molina y otros con Compañía Minera del Pacífico S.A.”, rol N ${ }^{\circ}$ 3455-1992, Corte de Apelaciones de Copiapó. 
jurídico nacional. De acuerdo con la clasificación explicada al comienzo del presente trabajo, esta norma bien podría calificarse de horizontal, y pese a ello, es aplicada directamente por los tribunales nacionales en un caso concreto. Lo segundo, y que resulta más extraordinario, es que la norma se aplica directamente a un privado; incluso en derecho comparado las cortes son reacias a aplicar normas y principio internacionales directamente a particulares sin que exista legislación expresa de aplicación ${ }^{8}$.

\section{Areas protegidas y parques nacionales.}

Una buena parte de los casos que dicen relación con la implementación y aplicación del derecho internacional del medio ambiente en Chile se ha dado a propósito de la implementación y aplicación del Convención Internacional para la protección de la flora, la fauna y las bellezas escénicas naturales de América de 1940, ratificada por Chile mediante Decreto Supremo $\mathrm{N}^{\circ} 531$ de 1967 del Ministerio de Relaciones Exteriores, conocida como "Convención de Washington".

No es extraño que los casos relativos a proyectos que implican intervenciones en áreas protegidas, y especialmente en parques nacionales, provoquen extensas discusiones. Sin embargo, la jurisprudencia existente muestra que las normas de este tratado han sido pobremente analizadas y aplicadas en forma poco sistemática e irregular. Si bien en un comienzo existieron criterios adecuados de conservación, fallos más recientes muestran resultados contradictorios y con argumentos que no son especialmente convincentes?.

a) El primer caso, recurrentemente citado, es el conocido "Parque Nacional Lauca" o "Laguna Chungará" de Washington" y de la Convención sobre la protección del patrimonio mundial cultural y natural de la UNESCO. La Corte Suprema confirmó el 19 de diciembre de 1985 el fallo de la Corte de Apelaciones de Arica, que acogió el recurso de protección presentado por agricultores cercanos al Valle de Azapa en contra de las actuaciones de la Dirección de Riego y del Ministerio de Obras Públicas, que pretendían extraer agua del lago Chungará para vaciarlas en las lagunas del Cotacotani. Al dar protección al derecho consagrado en el

${ }^{8}$ Bodansky, Daniel, The Art and Craft of International Environmental Law (Cambridge, Mass., Harvard University Press,, 2010), pp. 217-218.

${ }^{9} \mathrm{El}$ artículo III de la "Convención de Washington" señala: "Los Gobiernos Contratantes convienen en que los limites de los parques nacionales no serán alterados ni enajenada parte alguna de ellos sino por acción de la autoridad legislativa competente. Las riquezas existentes en ellos no se explotarán con fines comerciales".

${ }^{10}$ Fallo de la Corte Suprema de fecha 19 de diciembre de 1985 en recurso de protección caratulado "Palza Corvacho, Humberto con Director de Riego de la Primera Región y otros". 
artículo $19 \mathrm{~N}^{\circ} 8 \mathrm{CPol}$., la Corte Suprema señaló en su considerando $13^{\circ}$, luego de recordar que el lago Chungará forma parte del Parque Nacional del Lauca, que: "Las riquezas existentes en los Parques Nacionales no podrán explotarse con fines comerciales. En este caso, es cierto, la instalación de una estación de bombeo y la extracción que se ha hecho y que se propone continuar no tiene por fin primordial una explotación comercial pues su finalidad es proveer de más agua a la agricultura de Azapa y de más agua a la central hidroeléctrica de Chapiquina, pero es evidente, también, que ello se traducirá en una fuente de entradas fiscales [...]". El fallo de la Corte Suprema concluye haciendo una expresa referencia a la necesidad de dar cumplimiento a las obligaciones asumidas por el Estado de Chile, y que la paralización ordenada se fundamenta en "la existencia de los Convenios Internacionales [...] Convenciones y Acuerdos que requieren de una interpretación y aplicación cuidados a departe del gobierno por estar en juego la fe internacional" (considerando $\left.16^{\circ}\right)^{11}$.

El entusiasmo de la Corte Suprema por la aplicación directa de la Convención de Washington, al menos en los términos recién expuestos, claramente ha disminuido. Ello se puede apreciar claramente en los casos "Palmar Correntoso" y "Proyecto Catanave".

b) En el Caso "Palmar Correntoso" 12 la Corte Suprema finalmente rechazó el recurso de protección contra la resolución de calificación ambiental dictada por la entonces COREMA de la X Región, por la cual se autorizó el proyecto que consistía en la construcción y operación de una central hidroeléctrica de pasada de $13 \mathrm{MW}$ emplazada en los ríos Correntoso y Pulelfu. Las obras de bocatoma y parte de las tuberías de conducción de agua se ubicarían en el extremo sur poniente del Parque Nacional Puyehue. Con este fallo se autorizaba así la realización de actividades de generación eléctrica dentro de este Parque Nacional. El argumento de la Corte es bastante sencillo y lineal: el artículo 10 letra p) de la Ley $\mathrm{N}^{\circ} 19.300$, de Bases generales del medio ambiente, dispone que la ejecución de obras, programas o actividades en parques nacionales deben ingresar al SEIA: "como surge del tenor de la norma transcrita, se puede concluir que es posible realizar proyectos u obras en parques

\footnotetext{
${ }^{11}$ Continúa el mismo considerando: "Esta Convención y por tanto la ley chilena hacen diversos distingos o clasificaciones de lugares protegidos entre los que se encuentran los Parques Nacionales, que son regiones establecidas para la protección y conservación de las bellezas escénicas naturales y la flora y fauna de importancia nacional puestas bajo vigilancia oficial para que el pueblo pueda disfrutar mejor de ellas". La sentencia no solo se refirió a las categorías protegidas por la "Convención de Washington" de 1940, sino que también lo hizo respecto de la Convención UNESCO sobre la Protección del patrimonio mundial cultural y natural, de 1972, en su considerando $14^{\circ}$.

${ }^{12}$ Fallo de la Corte Suprema de fecha 8 de enero de 2009, rol N $6397-2008$, recurso de protección “contra la COREMA de la Región de Los Lagos”.
} 
nacionales y otras áreas protegidas. Lo exigido, conforme al marco jurídico que rige a esas unidades o áreas, es que la calificación favorable de tales proyectos sea precedida de una rigurosa evaluación de parte de la autoridad ambiental, a fin que sólo pueda ejecutarse bajo ciertas condiciones y exigencias en defensa del uso racional de los recursos naturales existentes" (considerando $7^{\circ}$ ).

Llama la atención que la Corte Suprema omitió totalmente en este caso pronunciarse respecto a la aplicación de la Convención de Washington, pese a que los recurrentes alegaron que la autorización administrativa vulneraba un tratado internacional vigente y ratificado por Chile. En realidad ni la Corte de Apelaciones ni la Corte Suprema se pronunciaron respecto a este argumento. Como puede apreciarse en la última parte del considerando Séptimo recién citado ${ }^{13}$, el fallo de la Corte Suprema rechaza el recurso por consideraciones que dicen relación con una amplia deferencia respecto del control de actos administrativos ambientales en el contexto del SEIA, y por la cual hasta hace muy poco las cortes se limitaron a comprobar que existiera una evaluación de impacto ambiental medianamente formal, sin analizar mayormente el fondo de dicha evaluación ni la adecuación de las medidas de mitigación impuestas al proyecto (en adelante "criterio de la deferencia").

En cuanto a la omisión a toda consideración respecto de la aplicación de la Convención de Washington, ella resulta inquietante. Una explicación plausible lleva a elucubrar que la Corte considera que esta Convención fue tácitamente derogada en este punto por la Ley $\mathrm{N}^{\circ} 19.300$, lo cual es algo bastante complejo de sostener -sin mencionar las consecuencias, al menos teóricas, en relación con una eventual responsabilidad internacional del Estado de Chile-. Otra opción más real sea que la Corte no quiso entrar a analizar este argumento, teniendo otros a los cuales recurrir para llegar a la misma conclusión y rechazar el recurso.

c) En el caso "Proyecto Catanave"14, la Corte Suprema, con fecha 16 de junio de 2011, confirmó el fallo de la Corte de Apelaciones de Arica de fecha 4 de marzo de 2011, que rechazó el recurso de protección interpuesto por la

${ }^{13}$ Dice el considerando $7^{\circ}$ del fallo citado: "En otras palabras, por lo que se debe velar es que las actividades que se realicen dentro de los parques nacionales sean compatibles con los objetivos de dichos espacios de preservación de las bellezas naturales y de la flora y fauna asociadas. En este caso, el proceso de evaluación de impacto ambiental a que fue sometido el proyecto en cuestión y que concluyó en las Resoluciones $N^{\circ} 380$ y 390, implicaron la imposición a su titular de una serie de condiciones y exigencias que, conforme a lo resuelto por la Corema X Región, apuntan a eliminar los efectos adversos de las obras que se pretenden construir". Para la Corte, en este caso, limitarse a constatar que la resolución de calificación ambiental imponía la ejecución de medidas de mitigación para el titular del proyecto constituyó un elemento suficiente de protección ambiental.

${ }^{14}$ Recurso de protección "Municipalidad de Putre con COREMA de Arica y Parinacota”, rol N²262-2011, Corte Suprema. 
Municipalidad de Putre en contra de la resolución de calificación ambiental (RCA) $N^{\circ} 73$ de 2010, de la COREMA de Arica y Parinacota, que a su vez autorizó el proyecto Exploración Minera Catanave de la empresa Southern Copper Corporation. El proyecto en cuestión consistía en actividades mineras que se realizarían dentro de la Reserva Nacional Las Vicuñas, a 200 kilómetros al este de Arica y a unos 4.650 metros sobre el nivel del mar. Los recurrentes argumentaron -entre otras consideraciones- que se trataba de un área en la cual no podían ejecutarse actividades de esta naturaleza, de conformidad con los artículos 1 letra a), 1 letra b) y $1 \mathrm{~N}^{\circ} 2$ de la "Convención de Washington”. Asimismo, se alegó que el área estaba catalogada como Reserva de la Biosfera bajo la Convención sobre la protección del patrimonio mundial cultural y natural de la UNESCO Como parte de sus argumentos, los recurrentes invocaron el fallo "Lago Chungará".

La Corte de Apelaciones -en criterio confirmado por la Corte Supremarazonó apegada a la normativa aplicable directamente al SEIA, obviando otros cuerpos legales sobre los cuales pronunciarse: en la medida que la actividad esté supuestamente permitida por las normas que regulan dicho instrumento [artículos 10 letra p. y 11 letra e) de la Ley $\mathrm{N}^{\circ} 19.300$ ], basta que exista la evaluación: "la revisión de los aspectos técnicos de una evaluación ambiental corresponde primordialmente a la autoridad administrativa respectiva" (considerando $11^{\circ}$ ). La parte resolutiva del fallo no contiene referencia alguna a la "Convención de Washington", pese a invocarse por los recurrentes.

d) Ecientemente otros casos han vuelto a traer esta materia ante nuestros tribunales superiores. En el conocido recurso acerca del "Proyecto Hidroaysén" ${ }^{15}$, la Corte Suprema tuvo oportunidad de pronunciarse nuevamente acerca de la Convención de Washington como normativa directamente invocada en un litigio particular. Aquí la Corte sí se pronunció expresamente, pero elabora algunas distinciones que resultan al menos debatibles.

En sentencia de fecha 4 de abril de 2012, la Corte Suprema confirmó el fallo de la Corte de Apelaciones de Puerto Montt, rechazando los recursos de protección interpuestos por parlamentarios de la zona, asociaciones de pescadores artesanales y agrupaciones que intentaban paralizar el proyecto hidroeléctrico - al menos en su primera fase-, el cual había sido aprobado por resolución de calificación ambiental (RCA) $\mathrm{N}^{\circ} 225$ de 13 de mayo de 2011, de la Comisión de Evaluación Ambiental de la Región de Aysén. Como consta tanto del estudio de impacto ambiental (EIA) como de la RCA

15 "Antonio Horvath Kiss y otros con Comisión de Evaluación Ambiental de la Región de Aysén”, rol N 10220-2011, Corte Suprema. 
favorable, el proyecto alteraría la superficie del Parque Nacional Laguna San Rafael ${ }^{16}$, pues para llenar el embalse "Baker 2", debería inundar alrededor de 48,1 hectáreas del margen sureste del Parque.

En este caso, es interesante recordar que algunos recurrentes alegaron que las normas de la Convención de Washington tienen carácter de autoejecutables: sus normas son completas y detalladas, de manera que el artículo $3^{\circ}$ de dicha Convención no requeriría de ningún desarrollo administrativo posterior para hacerse cumplir en nuestro ordenamiento, ni de la dictación de otras leyes que la precisen y le den contenido.

En primer término la Corte de Apelaciones de Puerto Montt, en fallo de fecha 6 de octubre de 2012, se apegó rigurosamente al criterio hasta entonces sustentado por la Corte Suprema en el caso "Palmar Correntoso": "lo que se exige es que la calificación favorable de dichos proyectos sea precedida de una rigurosa evaluación por la autoridad ambiental a fin de que sólo pueda ejecutarse bajo ciertas condiciones y exigencias en defensa del uso nacional de los recursos naturales existentes" (considerando $\left.28^{\circ}\right)^{17}$. Luego la Corte Suprema, al confirmar el fallo, reafirma que desarrollar proyectos como el pretendido en un parque nacional no se encuentra prohibido por la ley, según se desprende del artículo 10 letra $\mathrm{p}$ ) de la Ley $\mathrm{N}^{\circ} 19.300^{18}$.

Llama la atención que uno de los principales fundamentos para rechazar el recurso fueron: "Que en lo que se refiere a los otros reproches formulados al respecto, cabe considerar que la zona de afectación corresponde a 18 hectáreas del parque en que no hay presencia de especies arbóreas o arbustivas bajo categoria de protección, y que tampoco se afectan valores relevantes de flora y de fauna, geomorfológicos o paisajisticos, según informó CONAF a través de su oficio ordinario $N^{\circ} 344$, de fech a 15 de noviembre de 2010. Lo anteriorpermite

${ }^{16}$ Creado por Decreto Supremo N ${ }^{\circ} 475$ de 1989, del Ministerio de Agricultura como "Parque Nacional de Turismo"; luego el Decreto Supremo N 737 de 1983, del Ministerio de Bienes Nacionales lo reemplaza por "Parque Nacional”. El artículo 11 de la Ley de Bosques señala que "Las reservas de bosques y los parques nacionales de turismo (...) no podrán ser destinados a otro objeto sino en virtud de una ley".

${ }^{17} \mathrm{El}$ mismo considerando señaló: “[...] del examen de la Convención de Washington, aplicable en nuestro país por disposición del artículo 5 de la Constitución Politica de la República y vigente desde el 12 de octubre de 1967 en virtud del Decreto Supremo No 531, de 1967, del Ministerio de Relaciones Exteriores, como de la revisión de la Ley de Bosques, no se advierte la presencia de impedimentos para ejecutar obras o actividades en un parque nacional".

${ }^{18}$ Para la Corte Suprema: "lo que busca la norma es que la actividad que se va a desarrollar sea lícita y no contravenga el ordenamiento jurídico, pero en atención a que se desarrollará en un parque nacional u otra área colocada bajo protección oficial debe someterse a un estudio de impacto ambiental, tal como ha ocurrido en autos [...]" (considerando $\left.11^{\circ}\right)$. 
concluir que no puede aseverarse la utilización de recursos del parque con fines comerciales, pues éstos no se encuentran presentes en el área. Dicho organismo (la CONAF) sostuvo también que la inundación no atenta contra el espiritu de la Convención de Washington, ya que no afecta paisajes de incomparable belleza, formaciones geológicas extraordinarias u objetos naturales de interés cientifico o histórico, ni causaria la extinción de las especies que ocup an la superficie a inundar" (considerando $13^{\circ}$ ). El argumento de la Corte en este punto parece débil: resulta difícil sostener que por no explotarse especies arbóreas en la parte del Parque Nacional que se utilizaría para ejecutar el proyecto aprobado no se está frente a una actividad evidentemente comercial, en tanto el objeto del proyecto es la generación de electricidad.

Dicho esto, es cierto que la realización de actividades de explotación de recursos naturales en parques nacionales y otras categorías de protección reconocidas en la "Convención de Washington" requiere también el análisis de otras normas, entre ellas el artículo 17 CM. y el 10 de la Ley de bosques de 1931 (Decreto Supremo No 4363 de 1931, del entonces Ministerio de Tierras y Colonización). Lo mismo puede decirse de los artículos 11 de la Ley $\mathrm{N}^{\circ} 19.300$, letra d), y del Reglamento del SEIA, artículo 2 letra a). Interpretar armoniosamente todas estas normas resulta una tarea difícil, lo cual conlleva problemas jurídicos de importantes consecuencias prácticas ${ }^{19}$. Sin embargo, los criterios presentados por la Corte Suprema en los últimos casos citados no analizan realmente la situación del tratado: se descarta la aplicación del instrumento internacional por aplicación de otros textos legales y -en el caso "Hidroaysén"- atendido que no se cumpliría uno de los requisitos del artículo III de la Convención de Washington para prohibir dichas actividades (que señala que las riquezas de los parques nacionales " $n o$ se explotarán con fines comerciales") ${ }^{20}$.

${ }^{19}$ Una interpretación armónica debería considerar que, desde una perspectiva estrictamente ambiental, la elaboración de un estudio de impacto ambiental no basta para evitar impactos negativos considerables o alteraciones significativas del entorno, ni menos de aquellos sensibles. Considerando la redacción de las normas de la "Convención de Washington” y las características conceptuales de algunas áreas protegidas, el órgano jurisdiccional debería al menos controlar atentamente si las medidas de mitigación son adecuadas, atendida la naturaleza del lugar donde se pretende realizar tales actividades.

${ }^{20}$ Otro caso que resulta interesante destacar en relación con la aplicación directa de la "Convención de Washington", pero en una categoría distinta, tiene que ver con los monumentos naturales. En el caso por daño ambiental "Fisco con Bosques Arauco S.A.", rol N $135-2010$, la Corte de Apelaciones de Concepción, conociendo de los recursos de apelación y de casación en la forma interpuestos por el demandado, confirmó que Chile suscribió la "Convención de Washington", la cual se encuentra vigente en Chile y que define los monumentos naturales, y en ese contexto, el Decreto Supremo 


\section{Aplicación de otras fuentes del derecho internacional: los principios del} derecho internacional del medio ambiente.

Los tratados no son la única fuente de derecho internacional, y tampoco es cierto que sea la única que pueda aplicarse en el ámbito interno: si bien no es una materia especialmente clara, pueden sumarse otras fuentes bien conocidas por la práctica y doctrina internacional, tales como la costumbre y los principios generales del derecho ${ }^{21}$. El grado de aplicación que estas fuentes no tradicionales tienen en el derecho nacional de un Estado dependerá de la forma como éste los recibe o incorpora, sea a través de actos legislativos o administrativos o mediante su aplicación directa por el juez en un caso concreto $^{22}$.

Existe literatura internacional y en Derecho comparado que analiza el rol de los principios en la evolución del derecho ambiental y en la gestión del medio ambiente en general ${ }^{23}$. Tanto en el ámbito internacional como nacional puede decirse que ha ocurrido algo medianamente parecido: no hay un solo texto que indique de forma perentoria cuáles son los principios ni su ámbito de aplicación, su rango legal y sus contornos exactos. Es cierto, también, que muchos de los principios y conceptos comunes al derecho ambiental se han originado principalmente en el ámbito internacional, pero ello no impide que puedan existir principios propios del derecho nacional, o que la aplicación nacional de un principio no pueda tener matices respecto de sus versiones originales.

Still y McGillivray entregan una visión bastante acertada que ayuda a poner a los principios en contexto: "As a response to some of the problems of approaching environmental law or decisions from any one particular perspective, attempts have been made to formulate general concepts and principles that can accommodate at least some of the features of these various

N 43 de 1990 del Ministerio de Agricultura declaró como tal a la Araucaria Araucana, prohibiendo su corta. De esta forma la misma "Convención de Washington", implementada mediante esta prohibición contenida en el Decreto supremo $\mathrm{N}^{\circ} 43$ de 1990, sirvió de base para condenar en este caso a los demandados por daño ambiental, el cual fueron condenados a reparar. ¿Podía un acto administrativo prohibir la corta de una especie arbórea sin mayor base legal? Curiosamente, la simple lectura del Decreto supremo $\mathrm{N}^{\circ} 43$ de 1990 permite concluir que la administración invocó como fuente de su competencia, para estos efectos, la norma internacional.

${ }^{21}$ Artículo 38 del Estatuto de la Corte Internacional de Justicia.

${ }^{22}$ Véase Vargas Carreño, Edmundo, Derecho internacional público (Santiago, Editorial Jurídica de Chile, 2007).

${ }^{23}$ Véase, por ejemplo: SANDS, Philippe, Principles of International Law (2a edición, Cambridge, Cambridge University Press, 2003); y Hunter, David - Salzman, James - Zaelke, Durwood, International Environmental Law and Policy (3a edición, New York, Foundation Press, 2007). 
perspectives. The difficulty in doing this is that there has to be flexibility in the manner in which the principles can be interpreted - and this flexibility can create problems of certainty and precision. By their very nature, such principles need to be applied across sweeping expanses of environmental law and policy, and also beyond the environmental field"24. Por otra parte, los principios no operan de forma absoluta: indican más bien objetivos deseados, y su verdadero rango legal o fuerza vinculante dependerá de varios factores; desde luego, no todos ellos tienen la misma fuerza, y ella dependerá también de los cambios en las políticas ambientales internas. Algunos serán más bien principios de política ambiental, mientras otros podrán ser principios vinculantes que generan obligaciones ${ }^{25}$.

De esta forma hay principios que son comunes en lo internacional y nacional, como ocurre en aquellos Estados que han definido, incorporado y consagrado el principio precautorio como uno de los conceptos centrales de sus propias políticas y ordenamientos nacionales (caso del derecho comunitario europeo). Esto es algo que deberá analizarse caso a caso. El ordenamiento ambiental chileno reconoce ciertos principios aunque no siempre de forma directa $^{26}$. Hay otros principios, sin embargo, que constituyen parte de las bases fundamentales de nuestro ordenamiento jurídico ambiental y son coincidentes con un amplio reconocimiento en el plano internacional: es el caso del principio preventivo, reconocido en sentencias recientes - se verá enseguida- como un elemento central de nuestro ordenamiento ambiental.

Sin embargo, el análisis de algunos casos muestra que se trata de una materia escasamente abordada, caracterizada por un difuso manejo conceptual de los principios ambientales por parte de nuestra jurisprudencia. Se puede apreciar cierta confusión entre conceptos como precaución y prevención, los que en doctrina admiten claras diferencias; en otros casos pareciera que el desarrollo conceptual de algunos principios es una obra exclusiva del derecho interno, dejando de lado los vínculos doctrinarios e históricos con el derecho internacional del medio ambiente. Otras veces se hace referencia a ciertos principios sin un análisis acabado de su construcción dogmática, naturaleza, rango legal y efectos. Esto no parece una novedad. Bodansky y Brunnée constatan que, por ejemplo: "in many decisions, principles are not treated as international legal principles at all, but appear to be as reflecting

\footnotetext{
${ }^{24}$ Bell, Stuart - Mc Gillivray, Donald, Environmental Law (7a edición, Oxford, Oxford University Press, 2008), p. 54.

${ }^{25}$ Bell, S. - Mc Gillivray, D., cit. (n. 25), p. 54.

${ }^{26}$ Algunos obedecen al desarrollo internacional de este derecho, como ocurre con el concepto de desarrollo sustentable reconocido en el artículo $2^{\circ}$ letra g) de la Ley $\mathrm{N}^{\circ}$ 19.300: esta definición incorpora casi textualmente las versiones provenientes del derecho internacional.
} 
'common sense'. This has occurred notably with respect to the precautionary principle"27. Ello no es del todo criticable. Aun cuando muchas veces los principios del derecho internacional ambiental no tengan aplicación directa en un caso concreto, los mismos autores señalan que en derecho comparado se les ha usado al momento de la interpretación de normas nacionales, como argumentos de persuasión y no necesariamente desde su peso legal ${ }^{28}$.

En este sentido, es interesante constatar que algunos fallos recientes de nuestros tribunales han considerado la aplicación de ciertos principios cuando lo han estimado necesario y existen ciertos vacíos normativos. Esta es una materia en la cual los Tribunales Ambientales pueden jugar un rol muy importante en depurar estos argumentos, dotarlos de contenido más específico y certeza, indicando su alcance como herramientas de interpretación. Una rápida mirada a algunos de los siguientes casos, presentados con ocasión de los principios relevantes del derecho internacional ambiental, permitirá corroborar lo anterior:

a) Responsabilidad inter-generacional. La Corte Suprema, en fallo de fecha 19 de marzo de 1997, resolvió la aprobación del "Proyecto Río Cóndor", en el cual se acogió un recurso de protección interpuesto por el Movimiento Pro-Defensa del Medio Ambiente, en contra de la resolución de la entonces COREMA de la Región de Magallanes y Antártica Chilena que calificó favorablemente el proyecto de explotación forestal de bosque nativo presentado por la empresa Forestal Trillium. La Corte esgrimió como argumento uno de los principios propios del derecho internacional: la responsabilidad inter-generacional. Al razonar sobre el carácter de derecho colectivo público que involucra el derecho a vivir en un medio ambiente libre de contaminación, la Corte señala que "al dañarse o limitarse el medio ambiente y los recursos naturales, se limitan las posibilidades de vida y desarrollo no solo de las actuales generaciones sino también de las futuras" (considerando 13). Este es un reconocimiento a uno de los elementos que componen el concepto de desarrollo sostenible, de acuerdo con buena parte de la doctrina internacional ${ }^{29}$.

ii) Principio contaminador-pagador. En sentencia de la Corte de Apelaciones de Concepción de fecha 27 de agosto de 2012, en el caso "Central Termoeléctrica Pirquenes”, la Corte acogió el recurso de protección contra

${ }^{27}$ Bodansky, Daniel - BRunnéE, Jutta, Introduction: The Role of National Courts in the Field of International Environmental Law, en ANDERSON, Michael - GALIZZI, Paolo (editores), International Environmental Law in National Courts, British Institute of International and Comparative Law, Londres, 2002), p. 15.

${ }^{28}$ Bodanksy, D. - Brunnée, J., cit. (n. 28), p. 20.

${ }^{29}$ Para un análisis del concepto de desarrollo sustentable, véase: SANDS, Ph., cit. (n. 24). 
la RCA de la Comisión de Evaluación del Medio Ambiente del Bío-Bío que aprobó este proyecto, ordenando que el titular deberá ingresar nuevamente al SEIA mediante un estudio de impacto ambiental. El considerando 36) señala: "Con ello se dará cumplimiento además a los principios que inspiran la Ley $N^{\circ} 19.300$, a saber, el de la participación ciudadana, incluso en la evaluación de impacto ambiental (...). El principio de la internalización de los costos ambientales, conocido comúnmente como el principio de 'el que contamina paga' y que consiste básicamente en que el agente contaminador debe incorporar a sus propios gastos de producción lo que cuesta minimizar o controlar las emisiones contaminantes que genera (...)".

iii) Principio preventivo. La Corte ha aplicado recientemente el principio de prevención en al menos dos casos que han despertado la atención de quienes ejercen el derecho ambiental, y en uno de ellos como un fundamento directo de la decisión. El caso "Central Castilla" no tuvo por objeto directo la aplicación del derecho internacional ni principios propios del derecho internacional del medio ambiente; sin embargo, en uno de los fundamentos más importante en la decisión de declarar que el acto administrativo impugnado fue ilegal y arbitrario, la Corte Suprema señaló en su considerando Vigésimo octavo:"Que en la perspectiva de lo razonado, singular importancia cobra uno de los principios que inspiraron la Ley $N^{\circ} 19.300$, desarrollados en el mensaje presidencial con el que se inició el Proyecto de Ley de Bases del Medio Ambiente, esto es, el Principio Preventivo, según el cual'se pretende evitar que se produzcan problemas ambientales. No es posible continuar con la gestión ambiental que ha primado en nuestro pais, en la cual se intentaba superar los problemas ambientales una vez producidos'. En efecto, la conexión de ambas actividades cuya dependencia en la actualidad no es cuestionada, impide una aprobación separada de ambas, pues no puede soslayarse que la interconexión comprende la transferencia de Petróleo Diesely Carbón, ambos combustibles altamente contaminantes y susceptibles de alterar el medio ambiente por donde circularán".

iv) ¿Principio precautorio? Nuestra jurisprudencia no ha estado del todo ajena a la idea de precaución, pero sin particular claridad para identificar correctamente sus diferencias con el principio preventivo y las consecuencias que de ello derivan. Así por ejemplo, en el recurso de protección caratulado "Luis Pozo y otros contra Empresa Ferrocarriles Antofagasta a Bolivia", la Corte Suprema se pronunció el 4 de junio de 1998 sobre un caso de contaminación por acopio de plomo causado por la Empresa Ferrocarriles Antofagasta a Bolivia a niños de sectores aledaños a instalaciones de dicha empresa. $\mathrm{Al}$ acoger el recurso en favor de los afectados y ordenar el retiro de la totalidad del concentrado de plomo de sus recintos ubicados en Antofagasta, habilitando instalaciones alejadas de límites urbanos y especialmente acondi- 
cionadas para ello, la Corte se detiene en la relación de causalidad, cuestión particularmente compleja al momento de determinar las responsabilidades ambientales. Señala la Corte en el considerando $8^{\circ}$ del fallo, parte final, que "la prueba en materia ambiental se rige por el principio precautorio más que por la prueba cientifica propiamente tal". Se trata de una invocación bastante extraña: la Corte Suprema no define ni explica para qué serviría, en este contexto, el enfoque de precaución. La verdad es que este principio no tiene que ver directamente con la prueba sino primero con otras consideraciones. El hecho que en algunos casos internacionales y en derecho comparado se haya alegado una alteración de la carga de la prueba entre las consecuencias prácticas del principio de precaución ${ }^{30}$ no permite llegar a la conclusión de que estamos ante una norma simplemente procesal ${ }^{31}$.

b) Otro fallo a destacar es el caso "Central Hidroeléctrica Río Cuervo", de fecha 11 de mayo de 2012, en el cual la Corte Suprema revocó la sentencia de la Corte de Apelaciones de Coyhaique, ordenando así la realización de un informe adicional al estudio de impacto ambiental previo a enviar el proyecto a la Comisión de Evaluación Ambiental para aprobar o rechazar el proyecto (ejecutar un informe adicional de suelos en los términos indicados por SERNAGEOMIN). El considerando $6^{\circ}$ recuerda que el Mensaje de la Ley $\mathrm{N}^{\circ} 19.300$ se refiere al principio preventivo: "[...] mediante esteprincipio, se pretende evitar que se produzcan los problemas ambientales. No es posible continuar con la gestión ambiental que ha primado en nuestro país, en la cual se intentaba superar los problemas ambientales una vez producidos. Para ello, el proyecto de ley contempla una serie de instrumentos", entre los cuales está, por cierto, el sistema de evaluación de impacto ambiental. Continúa señalando que: "El principio preventivo, a diferencia del precautorio que actúa bajo supuestos ya comprobados, solamente requiere de un riesgo racional y evidente previamente demostrado, que sea verosimil de producirse sobre la base de estudios especializados que lo demuestren (...) para luego determinar la gravedad del mismo acontecimiento, que exista la posibilidad de sufrir un perjuicio importante, la alteración o el agravamiento de una determinada situación que, en el evento que ocurra, afectaria un interés legitimo"32. Existe mediana claridad

\footnotetext{
${ }^{30}$ Véase, por ejemplo, caso "Plantas de Celulosa, Argentina v. Uruguay", Corte Internacional de Justicia, sentencia de fecha 20 de abril de 2010.

${ }^{31}$ Acerca del contenido y estatus internacional del principio precautorio, véase, por ejemplo: SAnds, Ph., cit. (n. 24); y Bodansky, D., Art and Craft, cit. (n. 9).

${ }^{32}$ En la misma línea de lo anterior, el caso "Dunas de Concón”, en que la Corte Suprema revocó fallo de la Corte de Apelaciones de Valparaíso (27 de julio de 2012, causa rol N²138-2012): "No debe olvidarse que la Ley $N^{\circ} 19.300$ constituyó una ley marco en materia ambiental que se hizo aplicable a todas las actividades o recursos respecto de los cuales posteriormente se crearon leyes especiales y que se sustenta en principios que permiten
} 
en derecho internacional y comparado en que precaución y prevención son dos conceptos distintos ${ }^{33}$ (que el principio precautorio actúe "bajo supuestos ya comprobados" no es efectivo). Sin embargo, una construcción más estricta del principio de prevención podría llegar a consecuencias prácticas similares a aquellas propias del enfoque de precaución, sin que sea necesario agregar la incertidumbre que para muchos rodea a este último ${ }^{34}$.

Conviene entonces preguntarse por qué sería necesario construir un enfoque preventivo adecuado, y más específicamente, si esta construcción podría fundarse a partir de la aplicación de principios y normas propias del derecho internacional del medio ambiente.

b) La respuesta es relevante porque las consecuencias prácticas son reales. La importancia de un principio preventivo bien definido, aplicado regularmente por las Cortes -y pronto por los tribunales ambientales- al controlar actos de la administración puede apreciarse en toda su magnitud con un caso que hace algunos años cuestionó fuertemente la eficacia de la institucionalidad ambiental vigente, los instrumentos de evaluación de la Ley $\mathrm{N}^{\circ} 19.300$ y el rol de la administración y tribunales: el daño ecológico ocurrido con ocasión de las actividades de la planta de Celulosa Arauco (Celco) emplazada en el Río Cruces (comuna de San José de la Mariquina) ${ }^{35}$. El primer recurso de protección presentado por organizaciones ciudadanas alegó que la resolución atentaba contra la Ley $\mathrm{N}^{\circ} 17.288$ y la Convención

dar coherencia a la ley y sin los cuales se consideró que no se podía entender plenamente su real alcance y pretensiones ellos son: el principio preventivo; el principio que quien contamina paga; el gradualismo; el principio de la responsabilidad; el principio participativo; $y$ el principio de la eficiencia".

${ }^{33}$ Véase, por ejemplo: Wolfrum, Rudiger, International Environmental Law: Purposes, Principles and Means of Ensuring Compliance, en Morrison, Fred L. Wolfrum, Rudiger (editores), International, Regional and National Environmental Law (s.l., Kluwer Law International, 2000). Por ejemplo, en el principio de prevención se asume que el riesgo es conocido; en el enfoque de precaución no necesariamente lo es. De ello derivan una serie de consecuencias, desde el nivel de riesgo aceptable hasta la carga de la prueba.

${ }^{34}$ No es objeto de este artículo detenerse en un análisis acabado de las diferencias entre los principios de prevención y precaución, los orígenes y actual Estado en la evolución del derecho internacional y comparado. Para algunas legislaciones comparadas es claramente un principio, muchas veces en grado de norma. Su rango normativo en el derecho internacional y en especial desde el punto de vista de su inclusión como norma consuetudinaria, en cambio, es complejo de dilucidar.

${ }^{35} \mathrm{El}$ proyecto fue aprobado por resolución (RCA) N²79 de 1998 de la entonces COREMA de Los Lagos, e implicaba que los residuos industriales líquidos de dicha actividad (de alta temperatura, tóxicos) se verterían al río Cruces y Choromayo en un área declarada Santuario de la Naturaleza, protegida de conformidad con la Ley $\mathrm{N}^{\circ}$ 17.288 . 
de Ramsar, entre otros argumentos ${ }^{36}$, pero fue rechazado por la Corte de Apelaciones de Puerto Montt y confirmado por la Corte Suprema el 11 de mayo de 1999. La Corte señaló que la RCA se hacía cargo de las observaciones hechas por los recurrentes en su oportunidad, y condiciona el proyecto a una serie de requisitos y exigencias contenidas en la RCA respectiva $\left(\mathrm{N}^{\circ}\right.$ 279 de 1998). "Lo anteriorpermite concluir que el Santuario de la Naturaleza a que alude el recurso, debido a las condiciones impuestas al proyecto, queda protegido de los efectos de un eventual impacto negativo que pudiera producirse por su ejecución" (considerando $5^{\circ}$ ). La Corte guardó riguroso respeto por las consideraciones de la administración, sin entrar en el análisis de mérito técnico del proyecto ni de las medidas de control y mitigación impuestas como condición al proyecto (el "criterio de la deferencia", ya indicado): "[...] la resolución se dictó luego de un riguroso estudio de impacto ambiental (...) no pudiendo formar parte del recurso las cualidades técnicas que presente un proyecto" (considerando $\left.6^{\circ}\right)^{37}$.

${ }^{36}$ En este caso, la administración alegó que el hecho de incluir un humedal en la lista de la Convención Ramsar no perjudica los derechos soberanos de la parte contratante. Increíblemente, la COREMA también alegó que "los hechos planteados por la contraria constituyen una hipótesis no demostrada”. La Corte no se pronunció respecto de estos argumentos de fondo.

${ }^{37}$ No solo en el caso "Río Cisnes-Celco" la Corte desechó examinar el fondo de lo autorizado. En el fallo de fecha 19 de junio de 2002, de la Corte Suprema en recurso interpuesto por el alcalde de la Municipalidad de Portezuelo en contra de la resolución del Consejo Directivo de la CONAMA que calificó favorablemente el proyecto Complejo Forestal Itata, también de Celco (Caso "Celulosa Itata"), la Corte argumentó que una resolución adoptada por un ente colectivo no puede ser arbitraria "pues dicha decisión es el resultado del actuar de un ente colectivo, que ha contado con números antecedentes a la vista". Agrega que "Podrá estimarse equivocada, pero ello es de suyo discutible y no es posible de constatación empirica, pues en cuanto se pronuncia sobre situaciones de futuro, será entonces el tiempo el que diga si hubo un error o no. $Y$ si, contrariamente a lo que se ha estimado por la Resolución recurrida, se produce más adelante actos ilegales o arbitrarios y vulneratorios de las garantías constitucionales protegidas, será entonces, la ocasión precisa para acudir de protección o por otra vía que se estime adecuada" (considerando $7^{\circ}$ ). El voto de disidencia de la ministra Morales, que estuvo por acoger el recurso puesto que la resolución de calificación ambiental era arbitraria debido a su "falta de razonabilidad", recoge este punto al señalar que el estudio de impacto ambiental de la empresa no se hace cargo de ciertas sustancias y concentraciones en el cauce receptor final en donde "subyace la posibilidad de que se produzca un riesgo o un mal futuro, lo que sería irreparable tanto porque podría afectar aguas subterráneas, como por su efecto bioacumulativo en los animales y seres humanos". El fallo "Caso Celulosa Itata" no fue aislado. La Corte de Apelaciones de Valparaíso lo invocó al rechazar en fallo de 23 de noviembre de 2006, el recurso de protección interpuesto contra la resolución de la COREMA de Valparaíso que calificó favorablemente el proyecto Central Nueva Ventana, por el Consejo Ecológico de las Comunas de Puchuncaví y Quintero. La Corte señaló 
La planta de celulosa de Celco comenzó a operar en febrero de 2004. A los pocos meses fue posible apreciar la desaparición y desplazamiento de cisnes de cuello negro que habitaban los humedales de la zona cercana a la planta, al mismo tiempo que se cuestionaron ciertos cambios de operación que la empresa realizó en forma unilateral. Posteriores recursos de protección trataron sin éxito de impugnar y detener los aumentos de producción que la empresa ejecutó sin sujeción al SEIA ${ }^{38}$; ellos fueron rechazados por motivaciones que se alejan totalmente de un correcto enfoque preventivo. El 12 de enero de 2005 se presentó un recurso de protección en contra de las actuaciones de la empresa, específicamente la contaminación de la zona aledaña, de forma contraria a la RCA. La Corte de Apelaciones de Valdivia acogió el recurso y ordenó que la empresa debía someter modificaciones al proyecto de su planta al SEIA a través de un estudio. La Corte Suprema resolvió el 30 de mayo de 2005 que el recurso era extemporáneo, pero señaló algo más: aun si hubiese sido interpuesto dentro de plazo, no había pruebas que sea la planta de Celco la que estuviera afectando las poblaciones de cisnes afectadas que habitan en el humedal ${ }^{39}$.

Todo lo anterior se expone con la sola finalidad de mostrar que, ante posteriores resultados de daño ambiental, consideraciones acabadas de carácter preventivo (hasta llegar a algo no muy lejano al enfoque precautorio: riesgo conocido pero no necesariamente comprobado en todos sus aspectos, presunciones de riesgo, medidas de mitigación adecuadas y verificables, informes de seguimiento independientes) debieran formar parte del razonamiento no solo administrativo sino también judicial. El caso "Celco" llama particular-

en el considerando $13^{\circ}$ que: "el acto impugnado es incapaz por si de producir los efectos nocivos que los principios constitucionales intentan precaver [...], no es un acto de resultado material que 'acaso' produzca un menoscabo en el derecho a la vida y la integridad física y síquica de las personas".

${ }^{38}$ Recurso de protección rol N 1853-2005, "Vladimir Riesco Bahamondes y otros con Celulosa Arauco S.A.”, fallo de la Corte Suprema de fecha 30 de mayo de 2005; y recurso de protección rol N 5928-2006, “Wladimir León Falfán con COREMA de la Décima Región de Los Lagos”, fallo de la Corte Suprema de fecha 11 de diciembre de 2006.

${ }^{39}$ Corte Suprema en dicho fallo, considerando $7^{\circ}$ : "Que, desde luego, no hay prueba alguna que el Río Crucesy, en lo que interesa, en Santuario de la Naturaleza Carlos Andwandter, haya sido contaminado por Celulosa Arauco S.A. al operar su planta de San José de la Mariquina o que exista una amenaza de contaminación, término este último al que hay que darle su significado legal de acuerdo con la letra c) del artículo $2^{\circ}$ de la ley $19.300^{\prime \prime}$. El considerando $8^{\circ}$ señala: "[...] las aguas del Cruces presentan una alta concentración de hierro, que afecta una planta llamada 'luchecillo' (Egeria Densa), que constituye la principal fuente de alimento de los cisnes de cuello negro [...]. Al disminuir la cantidad de luchecillo, los cisnes mueren por desnutrición o emigran, encontrándose en los higados de dichos animales altas concentraciones de hierro". 
mente la atención porque se trató de un área sujeta a protección oficial del Estado como sitio Ramsar y Santuario de la Naturaleza (Ley $N^{\circ}$ 17.288). $\mathrm{Si}$ aquí no se aplicaron consideraciones realmente preventivas será difícil esperarlo en otras parcelas de la gestión ambiental. El derecho internacional y algunos de sus principios pueden ayudar a construir esta argumentación, necesaria en los casos de categorías protegidas, al menos mientras no exista un cuerpo legal que regule con claridad este tipo de áreas ${ }^{40}$.

\section{Los nuevos Tribunales Ambientales}

EN LA REFORMA A LA INSTITUCIONALIDAD AMBIENTAL: ¿HAY ESPACIO PARA LA IMPLEMENTACIÓN JUDICIAL DEL DERECHO INTERNACIONAL DEL MEDIO AMBIENTE?

\section{Generalidades.}

La Ley $\mathrm{N}^{\circ}$ 20.600, publicada en el Diario Oficial 28 de junio de 2013, completa la ambiciosa reforma iniciada formalmente en 2008. Aunque las críticas a la institucionalidad ambiental que existía hasta la publicación de la Ley $\mathrm{N}^{\circ} 20.417$ son antiguas, el proceso de acceso de Chile a la OCDE aceleró los cambios en esta materia. El informe sobre Evaluación de Desempeño Ambiental de Chile expuso a la evaluación y cumplimiento ambiental como una de las debilidades de nuestra organización institucional, señalando que era necesario fortalecer y ampliar considerablemente las instituciones ambientales, en especial la fiscalización: "una politica de fiscalización de la normativa ambiental sobre la base de la coordinación de los órganos sectoriales de supervisión y control no es la solución institucional más eficazpara asegurar su cumplimiento" 41 .

Es cierto que la idea de crear uno o más Tribunales Ambientales especializados no estuvo en el diseño original que proponía los cambios sustantivos hoy conocidos. Solo cuando aparece claro que se crearía un poderoso y autónomo órgano de fiscalización con potestades sancionatorias, comienza a surgir la idea de un control jurisdiccional especializado respecto de los actos administrativos sancionatorios de la que sería la Superintendencia del Medio Ambiente ${ }^{42}$.

${ }^{40}$ Sabido es que la Ley $N^{\circ} 18.362$ no está vigente. La futura creación del Servicio de Biodiversidad y Áreas Silvestres Protegidas puede convertirse en una oportunidad para aportar mayor coherencia a nuestra regulación de áreas protegidas en general.

${ }^{41}$ Organización para la Cooperación y el Desarrollo Económico, Evaluación del Desempeño Ambiental: Chile (Environmental Performance Reviews, CEPAL, Chile, 2005), p. 18.

${ }^{42}$ Ver el "Mensaje" (28 de octubre de 2009) y la historia de Ley $N^{\circ} 20.600$. Fue en el Senado donde se acuerda la creación de un órgano jurisdiccional cuyas labores serían: $i$ ) 
En cuanto al rol de los Tribunales Ambientales y la implementación del derecho internacional, hay buenas razones para sostener que la existencia de estos tribunales será un elemento positivo para el desarrollo de una jurisprudencia elaborada y uniforme en estas materias temas, aun cuando, desde luego, el hecho de contar con tribunales especializados no hará por sí mismo que prolifere la judicialización de casos en materias relacionadas con el derecho internacional del medio ambiente:

a) La especialidad en la materia. El hecho que se trate de tribunales ambientales que conocerán aspectos específicos de la gestión ambiental es un gran avance. De lo dispuesto en el artículo 17 letras a) y b) de la Ley $\mathrm{N}^{\circ} 20.600$ se aprecia también que se está en presencia de un tribunal casi exclusivamente de lo contencioso-administrativo. Esto no es casualidad: el derecho ambiental en Chile es, en su parte sustancial -es decir, funcionamiento de los instrumentos de gestión ambiental-, un descendiente directo y no emancipado del derecho administrativo ${ }^{43}$.

b) Jueces especializados. Tal vez sea la composición de los Tribunales Ambientales lo que permita predecir que, enfrentados a casos donde se invoquen normas de derecho internacional, los jueces entrarán al análisis de fondo de estos planteamientos. El artículo $2^{\circ}$ de la Ley $N^{\circ} 20.600$ señala que los ministros de los Tribunales Ambientales "deben haberse destacado en la actividad profesional o académica especializada en materias de Derecho Administrativo o Ambiental". Contar con jueces especializados que conocen o debieran conocer los principales conceptos y elementos del derecho ambiental, lo que incluye por cierto sus relaciones con el derecho internacional (históricas, conceptuales, de principios, regímenes regulatorios aplicables a Chile, entre otras), debiera traer como consecuencia que los jueces contarán con el conocimiento y habilidades para analizar seriamente los argumentos de fondo presentados por las partes referidos a la aplicación de tratados ambientales.

actuar como órgano de control jurisdiccional de las decisiones de la Superintendencia; ii) resolver las controversias contenciosas administrativas en materia ambiental, y (c) resolver las demandas por daño ambiental. "Mensaje" presidencialen: Historia de la Ley $N^{\circ} 20.600$ ( Biblioteca del Congreso Nacional), p.7.

${ }^{43} \mathrm{Si}$ bien es positivo contar con un órgano de control especializado de los actos de la administración ambiental, esta figura plantea nuevamente la vieja interrogante de si atomizar el control jurisdiccional de los actos de la administración sin que exista un real tribunal de casación unificador debilita nuestro sistema de control a través de la fragmentación de criterios y principios que deberían ser aplicados uniformemente en todos los ámbitos de lo administrativo. Dejando este cuestionamiento de lado, es indudable que la existencia de tribunales especializados debiera facilitar el conocimiento de aquellas materias que incluso dentro de esta disciplina parecen menos conocidas o estudiadas, como la implementación de tratados internacionales con contenido ambiental. 
c) Procedimiento adecuado. El detalle de las provisiones del título $3^{\circ}$ de la Ley $\mathrm{N}^{\circ} 20.600$, relativas a la presentación de las reclamaciones, el procedimiento, las medidas cautelares, notificaciones, informes y vista de la causa, entre otros, resulta apto para que los jueces conozcan y se pronuncien adecuadamente sobre el fondo de lo planteado por las partes. Además, la figura del amicus curiae, propia del derecho anglosajón y que no es extraña en algunas cortes y tribunales internacionales, probablemente alentará la presentación de argumentos relacionados con la implementación y cumplimiento de normas internacionales aplicables a los órganos de la administración.

\section{Normas que permitirán a los tribunales ambientales jugar un rol en la} implementación del derecho internacional del medio ambiente.

Si bien en casi todos los numerales del artículo 17 de la Ley N ${ }^{\circ} 20.600$ es posible pensar en casos hipotéticos vinculados con la aplicación del derecho internacional ambiental, es poco probable que ello ocurra con ocasión de recursos en contra de actos sancionatorios de la Superintendencia del Medio Ambiente ${ }^{44}$. Como ha sucedido hasta ahora, es muy probable que una buena parte de los casos en donde se ventilen estas materias sea a través de impugnaciones contra actos administrativos originados en el contexto del Sistema de Evaluación de Impacto Ambiental. Esta posibilidad podrá darse en alguna de las circunstancias previstas en los numerales 5) y 8) del artículo 17, en relación con el artículo 18 de la Ley $\mathrm{N}^{\circ} 20.600$ :

a) El número 5) del artículo 17 de la Ley $\mathrm{N}^{\circ} 20.600$ está relacionado con una modificación introducida por la Ley $\mathrm{N}^{\circ} 20.417$ a la posibilidad de impugnar actos en el contexto del SEIA. En efecto, el texto original de la Ley $\mathrm{N}^{\circ} 19.300$ no dejaba mayor espacio para la interposición de recursos por parte de quien no fuera el responsable del respectivo proyecto. El artículo 20 mantiene dicha estructura; sin embargo, el artículo 20 quinquies se refiere a los casos en que habiendo sido aprobado y estando en ejecución un proyecto, las variables evaluadas y contempladas en el plan de seguimiento sobre las cuales fueron establecidas las condiciones o medidas hayan variado sustantivamente en relación a lo proyectado o no se hayan verificado, casos en los cuales se podrá revisar la RCA, todo ello "con el objeto de adoptar las medidas necesarias para corregir dichas situaciones". En este caso, el acto administrativo que realice la revisión podrá ser impugnado ante los Tribunales Ambientales. Lo interesante es que el artículo 25 quinquies introducido

${ }^{44}$ La sanción se origina en la ley; aun cuando en Chile los tratados tengan al menos rango legal, la práctica indica que ningún juez aplicará una sanción directamente desde el texto de un tratado sin que exista al menos alguna norma nacional que de alguna forma la integre. Por lo demás, los tratados ambientales tampoco pretenden crear sanciones aplicables directamente. 
por la Ley $\mathrm{N}^{\circ} 20.417$ no limita esta facultad a la administración, sino que la extiende de la siguiente manera: "La resolución de calificación ambiental podrá ser revisada, excepcionalmente, de oficio o a petición del titular o del directamente afectado".

Cualquiera sea el significado que se le da este último concepto, está claro que no se trata solo del titular del proyecto. Es posible, por tanto, pensar en que en virtud de esta norma terceros afectados por la ejecución de un proyecto aprobado pero que se ejecuta de forma distinta o sobre la base de condiciones no previstas soliciten las medidas necesarias para corregir dichas situaciones. Así por ejemplo, tratándose de áreas silvestres protegidas o especies en alguna categoría de protección internacional reconocida en algún tratado, este argumento podrá ser considerado por la autoridad administrativa (director ejecutivo del Servicio de Evaluación Ambiental o Consejo de Ministros según corresponda, por remisión al artículo 20 de la Ley de bases del medio ambiente), y en caso que ello no ocurra, el acto administrativo será recurrible ante el tribunal ambiental competente. El artículo 18 número 7) señala expresamente que en este caso podrá intervenir como parte ante el tribunal ambiental "quien hubiese solicitado la invalidación, o el directamente afectado por la resolución que resuelva el procedimiento administrativo de invalidación”. No es necesario que el recurrente ante el tribunal ambiental haya participado o solicitado la invalidación del acto administrativo ambiental impugnado; basta que sea directamente afectado por la resolución.

b) El numeral 8) del citado artículo 17 permite impugnar resoluciones recaídas en procedimientos de invalidación respecto de actos administrativos de carácter ambiental ${ }^{45}$, entendiendo por tales "toda decisión formal que emita cualquiera de los organismos de la Administración del Estado mencionados en el inciso segundo del artículo $1^{\circ}$ de la Ley Orgánica Constitucional de Bases de la Administración del Estado, que tenga competencia ambiental y que corresponda a un instrumento de gestión ambiental o se encuentre directamente asociado con uno de éstos". El reconocimiento de esta causal es importante para lo que se ha venido discutiendo. En efecto, si bien la invalidación prevista en la Ley $\mathrm{N}^{\circ} 19.800$ de Bases de los procedimientos administrativos consiste en una potestad de la administración, ella también puede solicitarse a petición del administrado con lo cual "se erige en una vía de impugnación, incluso con un plazo privilegiado de 2 años, a diferencia de los recursos administrativos" ${ }^{46}$.

\footnotetext{
${ }^{45}$ Artículo 17 número 8) de la Ley N²0.600 dice: "Conocer de las reclamaciones en contra de la resolución que resuelva un procedimiento administrativo de invalidación de un acto administrativo de carácter ambiental. El plazo para la interposición de la acción será de treinta dias contado desde la notificación de la respectiva resolución".

${ }^{46}$ Bermúdez Soto, Jorge, Derecho administrativo general (Santiago, LegalPublishing, 2010), p. 136.
} 
Si el particular solicita la invalidación de un acto administrativo ambiental emanado de una autoridad sectorial en el contexto de un instrumento de gestión ambiental (el SEIA, por ejemplo), la resolución que recaiga en tal solicitud podrá recurrirse ante los Tribunales Ambientales. Teniendo presente que la regulación de los sujetos del procedimiento administrativo se construye a partir del concepto de interesado, será relevante los contornos de dicho concepto para dilucidar una posible comparecencia ante el tribunal ambiental, si alguien ya ha actuado como interesado ante el órgano administrativo que dictó el acto que se impugna. Por ejemplo, ocurriría si un tercero que logra la calidad de in te resado solicitare la invalidación de actos trámites en el marco del procedimiento de evaluación de impacto ambiental fundando en que dicho acto es ilegal por ser contrario a las normas de un tratado multilateral ambiental ${ }^{47}$. Como señala Bermúdez, "la LGBMA no establece recurso administrativo ni contencioso-administrativo a favor de los ciudadanos que se vean afectados en sus derechos o intereses por una resolución de calificación ambiental. Ello no obsta a que sea impugnada por las vías ordinarias administrativas, esto es, recursos administrativos de la LGPA, o contencioso-administrativas, acción de nulidad y recurso de protección, cuando ello sea pertinente" ${ }^{18}$. Tratándose de la invalidación de actos administrativos ambientales -sea a solicitud del administrado interesado o no- el acto que la resuelva será ahora impugnable ante el tribunal ambiental competente.

\section{Algunas incertidumbres que nuestros tribunales deberán aclararyposibles} criterios o principios que pueden invocarse.

a) Delimitación del recurso de protección frente al rol de los tribunales ambientales. En aclarar el rol que podrán desempeñar los Tribunales Ambientales como jueces internacionales, la primera interrogante se relaciona con lo expresado en el acápite anterior, y tiene que ver con la relación entre los Tribunales creados por la Ley N² 20.600 y la Corte Suprema, específicamente en el conocimiento de materias que podrán ser conocidas tanto por la vía del recurso de protección como por los recursos contencioso-administrativo previstos en la nueva ley.

Esta interrogante surge a partir de los legitimados activos para interponer ciertas acciones. Los artículos 17 y 18 de la Ley $\mathrm{N}^{\circ} 20.600$ no permiten expresamente que un tercero ajeno a un procedimiento de evaluación de impacto ambiental pueda impugnar directamente la resolución de calificación

${ }^{47}$ Por ejemplo, artículos 68, 69, 70 del Reglamento del SEIA, Decreto Supremo N ${ }^{\circ}$ 95 de 2001, Ministerio Secretaría General de la Presidencia de la República.

${ }^{48}$ Bermúdez Soto, Jorge, Fundamentos del Derecho ambiental (Valparaíso, Ediciones Universitarias de Valparaíso, 2008), p. 216. 
ambiental favorable al proyecto que se sometió al SEIA. Si bien se admite a quienes ejercieron su derecho a participación ciudadana impugnar la RCA si dichas observaciones no son consideradas, ello está lejos de permitir la impugnación directa del acto por quienes no sean los titulares del proyecto respectivo. En esto no hay grandes cambios respecto de lo que existía antes de la Ley $\mathrm{N}^{\circ} 20.417$, según se aprecia del artículo 17 numeral 6) de la Ley $\mathrm{N}^{\circ} 20.600$.

Sin embargo, la mayoría de las impugnaciones judiciales a los proyectos en cuestión (por mencionar algunos casos conocidos en los últimos años: Celco-Río Cruces, Río Cuervo, Barrancones, Hidroaysén, Castilla), provienen de quienes no fueron parte en el procedimiento administrativo, a través de recursos de protección. Si bien en muchos casos y durante demasiado tiempo las cortes mantuvieron un "criterio de deferencia" hacia la calificación técnica realizada por la autoridad administrativa, en el último tiempo se puede exhibir un cambio de actitud de la jurisprudencia, en virtud del cual la Corte Suprema ha entrado a analizar la legalidad de la evaluación misma y las medidas impuestas al proyecto (ver por ejemplo caso "Central Castilla”, ya citado).

Así las cosas tal vez hubiese sido prudente reconocer esta situación antes de permitir que, como resulta del texto de la Ley $\mathrm{N}^{\circ} 20.600$, los terceros afectados por una resolución de calificación ambiental favorable a un proyecto de inversión deban seguir presentado recursos de protección ante las Cortes de Apelaciones, con todo lo que ello significa: conocimiento por tribunales distintos de las mismas materias, potenciales diferencias de criterios, y falta de especialización y fragmentación, por mencionar algunos. Los efectos indeseados que eventualmente se provocarían como resultado de ampliar dicha legitimación activa se podrían también haber previsto o evitado; por ejemplo, con algunas limitaciones procedimentales o requisitos de comparecencia, como que el tercero haya efectivamente formulado observaciones en el marco del SEIA en su oportunidad. Como sea, esto hará que se mantenga el rol determinante de la Corte Suprema al conocer de los recursos contra los fallos de los Tribunal Ambientales y al conocer de la apelación del recurso de protección. Está por verse qué criterios adoptará nuestro más alto Tribunal al enfrentarse a este tipo de casos, especialmente si alguno de ellos está pendiente ante los Tribunales Ambientales.

b) Control y no simple deferencia. Asimismo, tanto los Tribunales Ambientales como la Corte Suprema deberían continuar con la reciente tendencia jurisprudencial de nuestro máximo tribunal y abandonar la deferencia como principio frente a los actos de la administración ambiental, por muy técnicos que ellos puedan parecer, siempre cuidando de no llegar 
a reemplazar aquella parte que corresponde al aspecto discrecional de la decisión administrativa.

Como explica Luis Cordero $\mathrm{Vega}^{49}$, en la relación entre examen y control de los actos administrativos ambientales, la jurisprudencia de la Corte $\mathrm{Su}$ prema ha pasado en los últimos años por tres momentos: $i$ ) durante mucho tiempo, sostuvo que la decisión de contenido técnico es de competencia exclusiva de la Administración; ii) luego, se sostuvo que si bien la decisión es de contenido técnico la Corte puede revisar los presupuestos procedimentales de la decisión estatal, realizando un control intenso de la discrecionalidad administrativa; y iii) algunos fallos parecen confirmar que la Corte puede adoptar decisiones de contenido más técnico, más allá de declarar la nulidad del acto de que se trate. Para Cordero Vega, en este último caso se está sustituyendo a la Administración en la solución, a pretexto de interpretación de una cláusula legal ${ }^{50}$.

Estamos de acuerdo con Cordero Vega en que el balance entre juzgar y administrar es delicado y que el juez debe definir los límites de sus competencias, para apreciar adecuadamente el problema que debe resolver, lo que no significa reconocer zonas exentas de control judicial, sino que tan solo una forma de aproximación del juez al conflicto que debe resolver, pudiendo anular las decisiones de los órganos técnicos, pero sin sustituir la competencia propia de la Administración al decidir el contenido de la solución final ${ }^{51}$. Por lo demás, el artículo 30 de la Ley $\mathrm{N}^{\circ} 20.600$, al indicar cuáles serán las atribuciones exactas del tribunal al conocer una reclamación contra actos administrativos, confirma lo anterior: el tribunal declarará la ilegalidad, anulará total o parcialmente el acto impugnado, ordenará que se modifique su contenido, pero en ningún caso determinará el contenido específico de un precepto de alcance general ni determinar el contenido discrecional de los actos de la administración ambiental.

Sin embargo, los fallos de la Corte Suprema que han sido objeto de algunas críticas recientes, y en particular el caso "Central Castilla", no necesariamente sustituyen la decisión de la administración. Si eso ocurre o ha ocurrido es en realidad una consecuencia indirecta de la decisión judicial: el acto fue considerado ilegal y las consecuencias de dicha decisión dejan poco espacio para la discrecionalidad del nuevo acto administrativo. Lo que tal vez se cuestione

${ }^{49}$ Cordero Vega, Luis, "Estudio preliminar". Corte Suprema y Medio Ambiente. ¿Por qué la Corte está revolucionando la regulación ambiental? en Jurisprudencia ambiental. Casos destacados, cit. (n. 3), p. 23.

${ }^{50}$ Ibíd., p. 23. Ejemplos de este último criterio serían los casos "Bocamina" (fallo de fecha 15 de junio de 2012, rol N 3141-2012) y "Central Castilla” (fallo de fecha 28 de agosto de 2012, causa rol $\mathrm{N}^{\circ} 1960-2012$ ).

${ }^{51}$ Cordero Vega, L., cit. (n. 3), p. 22. 
por algunos es la argumentación y el raciocinio de la Corte, al cual nuestra práctica forense no está acostumbrada: un principio inspirador de nuestro ordenamiento ambiental fundamenta la interpretación del texto legal, reprochando la forma en que fue entendido por la administración al impedir una evaluación ambiental adecuada, es decir, preventiva (por ejemplo, que exista claridad en la línea de base y en toda el área de influencia del proyecto).

Este último es uno de los puntos que probablemente tenga más consecuencias en la forma como se ejerce el control de los actos de la administración y que indirectamente podría tener repercusiones en la implementación judicial del derecho internacional. Lo anterior es relevante para este trabajo, porque en este tipo de decisiones se pueden presentar áreas en las cuales la jurisprudencia ha buscado argumentos no solo en el ordenamiento positivo, sino que también se ha vuelto hacia ciertos principios inspiradores de nuestra legislación. La mayoría de estos principios tienen su sustento, origen y construcción dogmática en el derecho internacional de medio ambiente, y eso debiera tenerse en cuenta. No se trata de importar conceptos o de imponer internamente normas de derecho internacional cuya naturaleza y rango legal son todavía discutidos, sino de buscar los fundamentos dogmáticos y conceptuales a principios que están recogidos en nuestro ordenamiento jurídico.

La importancia de tales principios no debería subestimarse: la Corte Suprema lo demostró en el fallo "Central Castilla”. Por otra parte, la discusión tiene consecuencias prácticas, como se aprecia en las negativas consecuencias del caso "Celco-Río Cruces". Lo anterior tiene particular importancia en el manejo y administración del SEIA: si bien la ley se limita a decir que es un procedimiento que solo busca contrastar la legalidad (artículo $2^{\circ}$ letra j) de la Ley $\mathrm{N}^{\circ} 19.300$ ), la doctrina y la jurisprudencia se han encargado de aclarar que uno de los principios fundamentales que dieron origen a este instrumento de gestión ambiental es precisamente la prevención. Así, las medidas de mitigación debiesen ser siempre preventivas, y el control judicial debería ir más allá de la deferencia. Si los costos de las medidas necesarias para prevenir y evitar un impacto ambiental negativo intolerable -o derechamente el daño ambiental-son demasiado altos, significa que el proyecto no podrá ejecutarse, y ello sin que sea necesario rechazar un proyecto formalmente: el SEIA no es el instrumento adecuado para diseñar política ambiental, energética o urbanística. No es posible reemplazar la decisión discrecional administrativa, salvo controlarla ahí donde lo permiten las herramientas propias del derecho administrativo. Pero controlar aspectos técnicos de las decisiones de la administración -que muchas veces incluyen elementos de legalidad- no significa avanzar hacia el temido "gobierno de los jueces". 


\section{Conclusiones}

Nuestras conclusiones pueden ser resumidas como sigue:

$1^{\circ}$ A pesar que se trata de una materia relevante para alcanzar la finalidad de protección ambiental acordada en el plano internacional, la jurisprudencia de nuestros más altos tribunales no muestra, salvo casos específicos, mayor desarrollo en la implementación de las obligaciones internacionales ambientales asumidas por Chile. Las razones se encuentran en la reticencia de nuestras Cortes para analizar argumentos que puedan implicar pronunciarse respecto de normas internacionales, a la naturaleza de nuestro principal contencioso-administrativo ambiental, y a la falta de especialidad y conocimiento respecto de las materias propias del derecho internacional del medio ambiente.

$2^{\circ}$ El desarrollo de esta materia puede perfeccionarse como una herramienta útil en el desempeño de nuestros instrumentos de gestión ambiental, especialmente si se considera que en el pasado nuestra jurisprudencia ha mostrado demasiada deferencia hacia los criterios de evaluación aplicados por la Administración, aun cuando a veces ellos se alejaran drásticamente del enfoque de prevención -en algunos casos, con negativas consecuencias ambientales-. Prueba de ello es la aplicación del principio preventivo -el que tiene amplio desarrollo en el derecho internacional del medio ambiente-, por la jurisprudencia reciente de la Corte Suprema como una herramienta de control en el marco del Sistema de Evaluación de Impacto Ambiental. Como señalan Palmer y Robb, la tendencia del derecho comparado muestra que las decisiones de las cortes rechazan la idea de que lo ambiental no es justiciable, o que se trate solo de "prerrogativas del ejecutivo" 52 .

$3^{\circ}$ Precisamente, con la próxima entrada en vigor de todos los Tribunales Ambientales y la conclusión de la reforma a la institucionalidad ambiental, el derecho ambiental en Chile comenzará su etapa de madurez. A propósito de la Ley $\mathrm{N}^{\circ} 20.600$, este trabajo ha planteado que la nueva judicatura ambiental podrá jugar un rol más relevante en la implementación de la normativa internacional aplicable en Chile, pues su diseño institucional, composición y procedimiento deberían favorecer una adecuada atención de los argumentos y consideraciones relacionadas con esta materia -algo que no ha sido así hasta ahora-.

$4^{\circ}$ Con todo, se explicó también que la Ley $N^{\circ} 20.600$, al descartar la posibilidad que terceros pudieran reclamar directamente ante los Tribunales Ambientales de las resoluciones de calificación ambiental favorables a un

\footnotetext{
${ }^{52}$ Palmer, Alice - RobB, Cairo, International Environmental Law in National Courts (Cambridge, Cambridge University Press, 2004), p. xiv.
} 
proyecto, se mantendrá el recurso de protección como un contenciosoadministrativo por defecto. El rol de la Corte Suprema, en este contexto, se convertirá en fundamental para unificar criterios ambientales de forma adecuada.

$5^{\circ}$ Finalmente, corresponde también analizar esta materia en una perspectiva más amplia, sin dejar de ver las consecuencias que derivan de la aplicación interna del derecho internacional. Cuando los tribunales se enfrenten a la necesidad de implementar o aplicar normas internacionales ambientales, lo importante es generar una relación constructiva entre derecho internacional y nacional. La implementación y aplicación del derecho internacional por parte de las cortes nacionales es una de las formas que tiene el Estado de contribuir al cumplimiento de una obligación internacional, con toda la seriedad que ello reviste. En la relación entre el derecho internacional y nacional del medio ambiente ello no es una excepción. En esta materia debiera surgir consenso en que los Tribunales Ambientales tienen una tarea importante que desempeñar.

La consideración de elementos propios de derecho internacional del medio ambiente por parte de los Tribunales Ambientales plantea un desafío a nuestra judicatura tanto especializada como común, pero ciertamente, puede inaugurar una nueva y fructífera etapa que es de esperar contribuya a nuestro acervo jurídico, a solucionar futuros conflictos ambientales sobre la base del desarrollo sustentable, y en definitiva, a mejorar y construir un mejor entorno natural para todos.

\section{BiBLIOGRAFÍA}

Bell, Stuart - Mc Gillivray, Donald, Environmental Law (7a edición, Oxford, Oxford University Press, 2008).

Bermúdez Soto, Jorge, Derecho administrativo general (Santiago, LegalPublishing, 2010).

Bermúdez Soto, Jorge, Fundamentos del Derecho ambiental (Valparaíso, Ediciones Universitarias de Valparaíso, 2008).

Bodanski, Daniel, en The Art and Craft of International Environmental Law (Cambridge, Mass., Harvard University Press, 2010).

Bodansky, Daniel - BrunnéE, Jutta, Introduction: The Role of National Courts in the Field of International Environmental Law, en ANDERson, Michael - GALIZZI, Paolo (editores), International Environmental Law in National Courts (Londres, British Institute of International and Comparative Law, 2002).

Cordero Vega, Luis, "Estudio preliminar”: Corte Suprema y Medio Ambiente. ¿Por qué la Corte está revolucionando la regulación ambiental? en Jurisprudencia ambiental, Casos destacados (Santiago, LegalPublishing, 2012).

Hunter, David - Salzman, James - Zaelke, Durwood, International Environmental Law and Policy (3a edición, New York, Foundation Press, 2007). 
OECD, Evaluación del Desempeño Ambiental: Chile. Environmental Performance Reviews (Naciones Unidas, CEPAL, Chile, 2005).

Palmer, Alice - Robb, Cairo, International Environmental Law in National Courts (Cambridge, Cambridge University Press, 2004).

SANDs, Philippe, Principles of International Law (2a edición, Cambridge, Cambridge University Press, 2003).

SLOss, David, The Role of Domestic Courts in Treaty Enforcement (New York, Cambridge University Press, 2009).

Vargas Carreño, Edmundo, Derecho internacional público (Santiago, Editorial Jurídica de Chile, 2007).

Wolfrum, Rudiger, International Environmental Law: Purposes, Principles and Means of Ensuring Compliance, en Morrison, Fred - Wolfrum, Rudiger (editores), International, Regional and National Environmental Law (s. 1., Kluwer Law International, 2000). 
